\title{
ADUBAÇÃO VERDE NO CONTROLE DE PLANTAS INVASORAS NAS CULTURAS DE ALFACE-AMERICANA E DE REPOLHO
}

\author{
Green manuring on the control of weeds in lettuce and cabbage crops
}

\author{
Anastácia Fontanétti1, Gabriel José de Carvalho², \\ Augusto Ramalho de Morais ${ }^{3}$, Karina de Almeida ${ }^{4}$, Whasley Ferreira Duarte ${ }^{5}$
}

\begin{abstract}
RESUMO
Objetivou-se com este trabalho verificar os possíveis efeitos físicos e/ou alelopáticos da adubação verde no manejo de plantas invasoras nas culturas posteriores de alface-americana e de repolho, visando à conversão para o sistema orgânico de cultivo. O experimento foi instalado no Setor de Olericultura da Universidade Federal de Lavras (UFLA), em Lavras -MG, no período de dezembro de 2001 a agosto de 2002. O delineamento experimental adotado foi o de blocos casualizados em esquema fatorial $4 \times 2$, com 3 repetições. O primeiro fator foi constituído pelas leguminosas mucuna-preta (Stizolobium aterrimum, Piper e Tracy), feijão-de-porco (Canavalia ensiformes DC), crotalária juncea (Crotalaria juncea L.) e pela testemunha (vegetação espontânea) e o segundo fator, pelas culturas de alface-americana 'Raider' e repolho 'Kenzan'. A parcela experimental teve a dimensão de 4 x $3 \mathrm{~m}$. Pelos resultados obtidos, nas condições em que foi desenvolvido o trabalho, pode-se concluir que as espécies utilizadas mostraram-se eficientes no controle de tiririca (Cyperus rotundus L.), especialmente a mucuna-preta e o feijão-de-porco, possivelmente por efeito alelopático, e o cultivo de repolho proporcionou maior redução da infestação de tiririca do que o de alface-americana.
\end{abstract}

Termos para indexação: Leguminosa, plantas daninhas, Cyperus rotundus, mucuna-preta, feijão-de-porco, Crotalária juncea.

\section{ABSTRACT}

The objective of this work was to verify allelopathical and physical effects of black velvet bean (Stizolobium aterrimum Piper e Tracy), jack bean (Canavalia ensiformes DC) and sunnhep (Crotalaria juncea L.) on the development of the weeds in American Lettuce and Cabbage crops. The experiment was performed at the Vegetables Sector of Universidade Federal de Lavras, in Lavras MG, from December 2001 to August 2002. The experimental design used was random blocks in the $4 \times 2$ factorial scheme with 3 repetitions. One factor consisted of the three leguminous, black velvet bean, jack bean and sunnhep, and the control (spontaneous vegetation); the other factor consisted of the cultures of Lettuce ('Raider'cultivar) and Cabbage ('Kenzan'cultivar). The results showed that the black velvet bean and jack bean controlled the sedge and the cabbage cultivation reduced the sedge infestation.

Index terms: Leguminous, weed, Cyperus rotundus L., black velvet bean, jack bean, sunnhep.

(Recebido para publicação em 11 de setembro de 2003 e aprovado em 8 de julho de 2004)

\section{INTRODUÇÃO}

As áreas olerícolas caracterizam-se pelo emprego contínuo do solo, com vários ciclos culturais que se desenvolvem em seqüência. Os solos geralmente são férteis, com abundância de irrigação e, por essas razões, nesses locais, predominam as plantas invasoras, que exibem características como rápido ciclo de desenvolvimento e elevada alocação de recursos a favor de estruturas reprodutivas (GRIME, 1979). A presença dessas espécies dificulta o uso e o manejo do solo pelos agricultores, o que tem incentivado o uso de herbicidas, elevado substancialmente os custos de produção, além de causar desequilíbrio no ecossistema. Entretanto, a preocupação com o ambiente e a qualidade de vida têm difundido amplamente as correntes de agricultura alternativa, entre elas a agricultura orgânica.

O sistema de produção orgânica tem crescido continuamente na última década, em razão de uma demanda cada vez maior por produtos orgânicos. Nesse contexto, são 15,8 milhões de hectares manejados organicamente em todo mundo. As estimativas atuais da FAO indicam um crescimento médio de $15 \%$ a $30 \%$ ao ano, podendo atingir $3,5 \%$ a $5,0 \%$ do mercado mundial de alimentos no ano de 2010, correspondendo a vendas de US\$ 61 a US\$ 94 bilhões em alimentos orgânicos. No Brasil, calcula-se que a área de cultivo orgânico esteja em torno de 100 mil hectares (AGRIANUAL, 2000).

1. Doutoranda em Fitotecnia, Universidade Federal de Viçosa/UFV - 36571-000 - Viçosa, MG, bolsista CNPq.

2. Dr., Professor do Departamento de Agricultura, Universidade Federal de Lavras/UFLA - Caixa Postal 3037 - Lavras, MG.

3. Dr., Professor do Departamento de Ciências Exatas, UFLA.

4. Mestranda em Fitotecnia, UFLA, bolsista CNPq

5. Graduando em Agronomia, UFLA 
As atuais mudanças na política global com diretrizes ecológicas, a crescente demanda por produtos orgânicos no mundo e as restrições impostas pelos países importadores quanto à qualidade e à segurança alimentar têm gerado a necessidade de estudos de técnicas alternativas para a produção de hortaliças que minimizem ou eliminem a utilização de adubos minerais e de agroquímicos.

A adubação verde destaca-se entre essas técnicas, por promover melhorias físicas, químicas e biológicas do solo, além de exercer importante efeito no manejo das doenças e de plantas invasoras pelos efeitos físicos e/ou alelopáticos.

As plantas de cobertura, utilizadas como adubo verde, geralmente formam uma barreira física para as plantas invasoras, competindo por água, luz e nutrientes e, quando manejadas adequadamente, podem diminuir o número de capinas manuais e evitar a utilização de herbicidas, adequando-se às normas orgânicas de produção.

Favero et al. (2001), estudando feijão-de-porco, feijão-bravo-do-ceará (Canavalia brasiliensis Mart ex Benth), mucuna-preta, lab-lab ( Dolichos lablab L.) e guandu ( Cajanus cajan (L.) Millsp) no controle de plantas invasoras, observaram que a mucuna-preta destacou-se das demais quanto à capacidade de recobrir o solo e abafar as plantas invasoras. Os mesmos autores também verificaram que houve uma mudança na dinâmica de sucessão de espécies nas parcelas cultivadas com essas leguminosas, indicando uma possível seleção das plantas invasoras imposta pelas mudanças edafoclimáticas promovidas por elas.

Entre essas mudanças, pode-se citar a redução das amplitudes diárias da variação térmica e hídrica na camada superficial do solo. Essa redução tem grande impacto na germinação de sementes de plantas invasoras, principalmente das chamadas ruderais, que ocorrem em áreas olerícolas (PITELLI e DURIGAN, 2003).

Além dos efeitos físicos, algumas plantas utilizadas como adubos verdes apresentam efeitos alelopáticos que contribuem para o manejo das plantas invasoras. A alelopatia é a produção de determinados compostos por organismos que, quando liberados no ambiente, têm impacto inibidor ou estimulador sobre outros organismos (GLIESSMAN, 2000). Os aleloquímicos podem interferir no metabolismo das plantas de várias maneiras, como reguladores de crescimento vegetal, inibidores de fotossíntese, desreguladores da respiração e do transporte na membrana celular e inibidores da atividade enzimática e protéica (EINHELLIG, 1986). A mucuna-preta, por exemplo, exerce forte e persistente ação inibidora sobre a tiririca (Cyperus rotundus) e picão-preto (Bi- dens pilosa L.), Lorenzi (1984) e Carvalho et al. (2002). Isso também foi observado para o feijão-de-porco que, mesmo em condições de baixa densidade de plantio, apresentou efeito alelopático inibidor sobre a tiririca (MAGALHÃES e FRANCO, 1962).

No entanto, em alguns trabalhos tem sido demonstrado que a utilização da adubação verde pode dificultar algumas práticas agrícolas, principalmente quando essas são consorciadas com a cultura principal. Silveira Neto (1993), avaliando a consorciação de adubos verdes de verão com o milho, verificou que a presença de leguminosas não diminuiu a infestação de plantas invasoras na primeira fase de desenvolvimento do milho, ao contrário, dificultou as capinas, aumentando o tempo gasto nessas operações. Porém, houve uma redução da população das plantas invasoras no final do ciclo e no período pós-colheita, resultando em menores problemas com ervas nas safras subseqüentes.

Neste trabalho, procurou-se verificar os possíveis efeitos da adubação verde no manejo de plantas invasoras nas culturas de alface-americana e repolho, visando à conversão para o sistema orgânico de cultivo.

\section{MATERIAL E MÉTODOS}

O experimento foi conduzido no período de dezembro de 2001 a agosto de 2002, no Setor de Olericultura do Departamento de Agricultura da Universidade Federal de Lavras (UFLA), em Lavras, MG.

O delineamento experimental adotado foi o de blocos casualizados em esquema fatorial $4 \times 2$, com 3 repetições. O primeiro fator foi constituído pelas leguminosas, mucuna-preta (Stizolobium aterrimum), feijão-de-porco (Canavalia ensiformes), crotalária juncea (Crotalaria juncea) e por uma testemunha (vegetação espontânea), e o segundo, pelas culturas de alface-americana, cultivar Raider, e repolho, cultivar Kenzan. A parcela experimental teve a dimensão de $4 \mathrm{~m} \mathrm{x} 3 \mathrm{~m}$.

O preparo do solo foi feito no sistema convencional, com aração e gradagem. Após quinze dias do preparo do solo, identificaram-se as espécies de plantas invasoras na área experimental, utilizando-se amostragens feitas em $1 \mathrm{~m}^{2}$ por parcela. Em seguida, a área foi capinada manualmente e, no dia 5 de dezembro de 2001, semearam-se a mucuna-preta e o feijãode-porco, com espaçamento de 0,50 m entre linhas e 0,20 m entre plantas, e a Crotalária juncea, com $0,50 \mathrm{~m}$ entre linhas e $0,05 \mathrm{~m}$ entre plantas. As parcelas da testemunha foram deixadas sem capinas até o plantio das hortaliças. 
As leguminosas foram roçadas e incorporadas ao solo com auxílio de uma grade de disco no dia 21 de março de 2002. Um mês após a incorporação, o solo foi gradeado e os canteiros para o plantio da alfaceamericana foram feitos manualmente. As hortaliças foram transplantadas no dia 02 de maio de 2002, utilizando, para a alface-americana, o espaçamento de $0,5 \mathrm{x}$ $0,3 \mathrm{~m} \mathrm{e}$, para o repolho, covas espaçadas de $0,6 \mathrm{x}$ $0,4 \mathrm{~m}$.

$\mathrm{Na}$ testemunha, utilizou-se adubação química baseada na análise de solo e de acordo com a recomendação para as culturas da CFSEMG (1999). Para a alface-americana, a adubação foi de $400 \mathrm{~kg} \mathrm{ha}^{-1}$ $\mathrm{P}_{2} \mathrm{O}_{5}, 150 \mathrm{~kg} \mathrm{ha}^{-1}$ de $\mathrm{K}_{2} \mathrm{O}$ e $150 \mathrm{~kg} \mathrm{ha}^{-1}$ de N. O nitrogênio foi parcelado colocando-se em $75 \mathrm{~kg} \mathrm{ha}^{-1}$ no plantio e 50 e $25 \mathrm{~kg} \mathrm{ha}^{-1}$ aos 30 dias e 45 dias após o plantio, respectivamente. Para o repolho, utilizaramse $100 \mathrm{~kg} \mathrm{ha}^{-1} \mathrm{P}_{2} \mathrm{O}_{5}, 100 \mathrm{~kg} \mathrm{ha}^{-1}$ de $\mathrm{K}_{2} \mathrm{O}$ e $150 \mathrm{~kg} \mathrm{ha}^{-1}$ de $\mathrm{N}$. O nitrogênio foi parcelado colocando-se $30 \mathrm{~kg}$ $\mathrm{ha}^{-1}$ no plantio e 30 e $45 \mathrm{~kg} \mathrm{ha}^{-1}$ aplicados aos 30,45 e 65 dias após o plantio, respectivamente. Também aplicou-se $1 \mathrm{~g}$ de ácido bórico por cova. Nas parcelas com as leguminosas, utilizou-se a adubação com composto orgânico na dose de $20 \mathrm{t} \mathrm{ha}^{-1}$ (peso úmido), em duas aplicações de $10 \mathrm{t} \mathrm{ha}^{-1}$, respectivamente, no plantio e 30 dias após o plantio, para ambas hortaliças.

Foi feita uma amostragem do material vegetal (parte aérea) das leguminosas, quando essas estavam em início da floração, e da vegetação espontânea em um $1 \mathrm{~m}^{2}$ por parcela. As amostras de massa fresca foram pesadas, sendo retirados $500 \mathrm{~g}$ de cada material para determinação de massa seca; o restante foi devolvido à área experimental. A massa seca foi obtida após secagem em estufa com ventilação de ar forçada à temperatura de $65^{\circ} \mathrm{C}$ por um período de 5 dias (até estabilização do peso).

Após o transplante das hortaliças, realizaram-se quatro contagens das plantas invasoras, por amostragem em $1 \mathrm{~m}^{2}$ por parcela, aos 15, 45, 65 e 95 dias. Depois de cada avaliação, foram realizadas capinas manuais em todas as parcelas.

As principais espécies de plantas invasoras observadas na área experimental, antes da semeadura das leguminosas, foram tiririca (Cyperus rotundus), com $56 \%$ de recobrimento, nabiça-roxa (Raphanus sativus L.), leiteiro (Euphorbia heterophylla L.), capimmarmelada (Brachiaria plantaginea (Link.) Hitchcok), picão-preto (Bidens pilosa), grama-seda (Cynodon dactylon L.) e caruru-de-mancha (Amaranthus viridis (L.) Pers).
Aos quinze dias após o transplante das hortaliças, as plantas invasoras que apareceram expressivamente foram a tiririca, a nabiça-roxa, o leiteiro e o trevo. Outras, como o capim-marmelada, picão-preto, grama-seda e caruru-de-mancha, foram computadas em um único grupo para efeito de análise estatística. Nas demais avaliações (45, 65 e 95 dias), apenas a tiririca e o trevo apareceram em maior quantidade, ao passo que a nabiça-roxa e o leiteiro passaram a fazer parte do grupo denominado outras plantas invasoras. Os dados de contagem das espécies tiririca, nabiça-roxa e leiteiro foram transformados utilizando a expressão $\sqrt{x}$; o trevo e o grupo outras plantas invasoras, a expressão $\sqrt{(x}+0,5)$, por serem as expressões mais indicadas para dados de contagem.

\section{RESULTADOS E DISCUSSÃO}

De acordo com a análise de variância para as coberturas vegetais (leguminosas e vegetação espontânea), verificou-se diferença significativa para as variáveis massa verde, massa seca e teor de massa seca.

A vegetação espontânea produziu menor quantidade de massa verde e massa seca, ao passo que as leguminosas não diferiram entre si na produção de massa verde. No entanto, a crotalária juncea apresentou maior produção e teor de massa seca em relação à mucuna-preta e ao feijão-de-porco (Tabela 1).

TABELA 1 - Produção de massa verde (MV), massa seca (MS) e teor de massa seca (TMS) das plantas de cobertura ${ }^{1}$. UFLA, Lavras, MG, 2002.

\begin{tabular}{lccc}
\hline \multicolumn{1}{c}{ Plantas cobertura } & $\begin{array}{c}\text { MV } \\
\left(\mathbf{t ~ h a}^{-\mathbf{1}}\right)\end{array}$ & $\begin{array}{c}\text { MS } \\
\left(\mathbf{t ~ h a}^{-\mathbf{1}}\right)\end{array}$ & $\begin{array}{c}\text { TMS } \\
(\mathbf{\%})\end{array}$ \\
\hline Crotalária juncea & $39,33 \mathrm{a}$ & $12,753 \mathrm{a}$ & $29,81 \mathrm{a}$ \\
Mucuna-preta & $42,43 \mathrm{a}$ & $8,50 \mathrm{~b}$ & $20,09 \mathrm{~b}$ \\
Feijão-de-porco & $35,86 \mathrm{a}$ & $7,51 \mathrm{bc}$ & $22,31 \mathrm{~b}$ \\
Vegetação espontânea & $22,75 \mathrm{~b}$ & $5,24 \mathrm{c}$ & $24,56 \mathrm{~b}$ \\
\hline
\end{tabular}

${ }^{1}$ Médias seguidas das mesmas letras na coluna não diferem entre si pelo teste de Tukey a $5 \%$ de probabilidade. 
A produtividade da massa verde da mucuna-preta e do feijão-de-porco obtidas foram maiores que as mencionadas por Alvarenga et al. (1995) e Oliveira et al. (2002). De modo geral, as produtividades dessas leguminosas superaram os limites propostos por Calegari (1995), que são para a mucuna-preta entre $10 \mathrm{e} 40 \mathrm{t} \mathrm{ha}^{-1} \mathrm{e}$ para o feijão-de-porco, entre14 e $30 \mathrm{t} \mathrm{ha}^{-1}$ de massa verde.

Já para a crotalária juncea, a produtividade de $39,33 \mathrm{t} \mathrm{ha}^{-1}$ foi inferior à mencionada por Alvarenga et al. (1995), que foi de 52,3 $\mathrm{t} \mathrm{ha}^{-1}$ de massa verde, com plantio em novembro, fato talvez relacionado à sensibilidade dessa leguminosa ao fotoperíodo. A crotalária juncea é uma espécie de dias curtos e o plantio em dezembro poderia ter diminuído sua produção de massa verde, por favorecer seu florescimento.

O teor de massa seca da mucuna-preta $(20,09 \%)$ e do feijão-de-porco $(22,31 \%)$ teve resultados equivalentes aos obtidos por Oliveira et al. (2002). Para a crotalária juncea, a produtividade de massa seca foi de $12,75 \mathrm{t} \mathrm{ha}^{-1}$, menor que a citada por Alvarenga et al. (1995) de 16,1 t ha ${ }^{-1}$ e maior que a obtida por Alcântara et al. (2000), que foi de $6,5 \mathrm{tha}^{-1}$.

Em relação às plantas invasoras, na primeira avaliação aos 15 dias após o transplante das hortaliças, verificou-se que para as espécies nabiça-roxa e tiririca houve diferença significativa apenas para o fator cobertura do solo. Já para o trevo, leiteiro e outras plantas invasoras, não houve diferença significativa para nenhum fator.

Para a nabiça-roxa, a mucuna-preta apresentou o melhor controle, quando comparada com a vegetação espontânea (testemunha). Já para a tiririca, todas as leguminosas utilizadas proporcionaram, igualmente, melhor controle do que a vegetação espontânea (Tabela 2).

Esses resultados provavelmente ocorreram pelo fato de as leguminosas terem apresentado maior produção de biomassa quando comparadas com a vegetação espontânea (testemunha). Além disso, possivelmente, a incorporação dessas provocou alterações físicas, as quais retardaram a emergência das plantas invasoras, como a redução das amplitudes diárias da variação térmica, hídrica e a incidência da luz solar na camada superficial do solo. Schimidt et al. (2002), comparando os adubos verdes mucuna-preta, feijão-de-porco, Crotalária juncea, vegetação espontânea e uma área em alqueive, verificaram que, sob palhada de Crotalária juncea, a temperatura média observada $\left(23,3^{\circ} \mathrm{C}\right)$ foi significativamente inferior às demais, tendo a área de alqueive atingido $41,9^{\circ} \mathrm{C}$. Entretanto, em alguns estudos, tem sido demonstrado que, para a tiririca, alguns centímetros de palhada de baixa densidade não são obstáculo para sua emergência (LORENZI, 1984). Por essa razão, o melhor controle exercido pelas leguminosas também pode estar associado a efeitos alelopáticos.

TABELA 2 - População de nabiça-roxa e tiririca em função das plantas de cobertura aos 15 dias após transplante das hortaliças ${ }^{1}$. UFLA, Lavras, MG, 2002.

\begin{tabular}{lcc}
\hline Plantas de cobertura & $\begin{array}{c}\text { Nabiça } \\
\text { (plantas /m²) }\end{array}$ & $\begin{array}{c}\text { Tiririca } \\
\text { (plantas /m²) }\end{array}$ \\
\hline Crotalária juncea & $12,16 \mathrm{ab}$ & $43,6 \mathrm{~b}$ \\
Feijão-de-porco & $13,33 \mathrm{ab}$ & $41,5 \mathrm{~b}$ \\
Mucuna-preta & $8,16 \mathrm{~b}$ & $25,5 \mathrm{~b}$ \\
Vegetação espontânea & $20,16 \mathrm{a}$ & $95,5 \mathrm{a}$ \\
\hline
\end{tabular}

${ }^{1}$ Médias seguidas das mesmas letras na coluna não diferem entre si pelo teste de Tukey, a $5 \%$ de probabilidade.

$\mathrm{Na}$ avaliação feita aos 45 dias, verificou-se interação significativa entre as plantas de cobertura e hortaliças, quanto à tiririca. Já para o trevo, não houve nenhum controle e, para as demais plantas invasoras, apenas as plantas de cobertura apresentaram efeito, independente das hortaliças cultivadas. Pelos dados da Tabela 3, observa-se que quando se cultivou repolho em sucessão ao feijão-de-porco, houve um melhor controle da tiririca. O mesmo ocorreu quando se cultivou alfaceamericana na área anteriormente cultivada com mucunapreta. Esse fato talvez seja explicado por possíveis efeitos alelopáticos sinérgicos do feijão-de-porco e do repolho e da mucuna-preta e alface-americana sobre a tiririca. No entanto, quando se analisa apenas o efeito das hortaliças no controle da tiririca, não se observou diferença significativa entre elas.

Segundo Magalhães e Franco (1962) e Carvalho et al. (2002), o feijão-de-porco e a mucuna-preta apresentam efeito alelopático sobre a tiririca. Lorenzi (1984) verificou apenas $31 \%$ de emergência de tiririca em área anteriormente cultivada com mucuna-preta e $100 \%$ de emergência em solo de área não vegetada com essa leguminosa. As culturas agrícolas também podem exercer efeito alelopático sobre determinadas espécies de plantas invasoras, como é o caso da cana-de-açúcar, cuja palhada exerce efeito supressor sobre o picão-preto e tiririca (LORENZI, 1984). 
TABELA 3 - População de tiririca em função das plantas de cobertura e das hortaliças aos 45 dias após o transplante' ${ }^{1}$ UFLA, Lavras, MG, 2002.

\begin{tabular}{ccccc}
\hline $\begin{array}{c}\text { Hortaliçasłplantas } \\
\text { cobertura }\end{array}$ & $\begin{array}{c}\text { Feijão-de-porco } \\
\left(\text { plantas } / \mathbf{m}^{2}\right)\end{array}$ & $\begin{array}{c}\text { Mucuna-preta } \\
\left(\text { plantas } / \mathbf{m}^{2}\right)\end{array}$ & $\begin{array}{c}\text { Crotalária juncea } \\
\left(\text { plantas } / \mathbf{m}^{2}\right)\end{array}$ & $\begin{array}{c}\text { Vegetação espontânea } \\
\left(\mathbf{p l a n t a s} / \mathbf{m}^{\mathbf{2}}\right)\end{array}$ \\
\hline Alface-americana & 35,00 a A B & 13,66 b C & 27,00 a B C & 62,00 a A \\
Repolho & 10,33 b B & 34,33 a A & 29,33 a A & 52,66 a A \\
\hline
\end{tabular}

${ }^{1}$ Médias seguidas das mesmas letras minúsculas na coluna e maiúsculas na linha não diferem entre si pelo teste de Tukey a $5 \%$ de probabilidade.

Para o grupo denominado outras plantas invasoras, verificou-se melhor controle quando se incorporou a Crotalária juncea, com média de 0,74 plantas $/ \mathrm{m}^{2}$, independente da hortaliça; as demais plantas de cobertura não diferiram estatisticamente entre si. Esse fato pode ter ocorrido devido à maior produção de biomassa dessa leguminosa que, mesmo depois da incorporação, formou uma camada de palha maior que as demais coberturas utilizadas, originando uma barreira física.

$\mathrm{Na}$ avaliação feita aos 65 dias após transplante das hortaliças, verificou-se que os fatores plantas de cobertura e hortaliças apresentaram efeito significativo, isoladamente, no controle de tiririca. Para o trevo, nenhum fator apresentou efeito significativo e, para as demais plantas invasoras, apenas as hortaliças interferiram significativamente no controle.

Observando a Tabela 4, verifica-se que, de modo geral, as leguminosas apresentaram melhor controle da tiririca quando comparadas com a vegetação espontânea. Todavia, a crotalária juncea e o feijão-de-porco destacaram-se mais que a mucuna-preta.

TABELA 4 - População de tiririca em função das plantas de cobertura aos 65 dias após transplantio das hortaliças ${ }^{1}$. UFLA, Lavras, MG, 2002.

\begin{tabular}{lc}
\hline \multicolumn{1}{c}{ Plantas de cobertura } & $\begin{array}{c}\text { Tiririca } \\
\text { tas/m² }\end{array}$ \\
\hline Crotalária juncea & $38,8 \mathrm{~b}$ \\
Mucuna-preta & $44,6 \mathrm{ab}$ \\
Feijão-de-porco & $31,8 \mathrm{~b}$ \\
Vegetação espontânea & $63,5 \mathrm{a}$
\end{tabular}

${ }^{1}$ Médias seguidas das mesmas letras não diferem entre si pelo teste de Tukey a $5 \%$ de probabilidade.

Segundo Almeida (1991), as plantas que produzem aleloquímicos, mesmo depois de mortas, conser- vam essas substâncias em seus tecidos, liberando-as lentamente. Quando atingem a concentração necessária no solo, exercem seu efeito alelopático. Dessa forma, podese inferir que, possivelmente, o efeito alelopático do feijão-de-porco e o da crotalária juncea são mais persistentes no solo, quando comparados com o efeito da mucuna-preta.

Para o fator hortaliça isoladamente, o repolho apresentou melhor controle sobre a tiririca em relação à alface-americana (Tabela 5). Esse fato pode estar relacionado à competição por luz e água dessa hortaliça com a tiririca, devido a sua maior área foliar e também a um possível efeito alelopático.

TABELA 5 - População de tiririca em função das hortaliças aos 65 dias após transplante ${ }^{1}$. UFLA, Lavras, MG, 2002.

\begin{tabular}{|c|c|}
\hline Hortaliças & $\begin{array}{l}\text { Tiririca } \\
\left.\operatorname{tas} / \mathbf{m}^{2}\right)\end{array}$ \\
\hline Alface-americana & $60,10 \mathrm{a}$ \\
\hline Repolho & $29,10 \quad b$ \\
\hline
\end{tabular}

${ }^{1}$ Médias seguidas das mesmas letras não diferem entre si pelo teste de Tukey a $5 \%$ de probabilidade.

Na última avaliação, aos 95 dias após transplante das hortaliças, verifica-se interação significativa dos fatores plantas de cobertura e hortaliças no controle de tiririca, ao passo que para o trevo e outras plantas invasoras, nenhum fator exerceu influência. Pelos dados da Tabela 6, observa-se que quando se cultivou repolho nas áreas antes cobertas com feijão-de-porco e vegetação espontânea, o número de plantas de tiririca foi reduzido. No primeiro caso, a explicação mais uma vez pode ser a de algum efeito alelopático sinérgico do repolho e feijão-de-porco sobre a tiririca. Já na área de vegetação espontânea, pode-se inferir que o repolho possivelmente exerceu efeito alelopático sobre a tiririca. 
TABELA 6 - População de tiririca em função das plantas de cobertura e das hortaliças aos 95 dias após transplante'. UFLA, Lavras, MG, 2002.

\begin{tabular}{|c|c|c|c|c|}
\hline $\begin{array}{c}\text { Hortaliças/plantas } \\
\text { cobertura }\end{array}$ & $\begin{array}{c}\text { Feijão-de-porco } \\
\text { (plantas/m²) }\end{array}$ & $\begin{array}{c}\text { Mucuna-preta } \\
(\text { plantas/m²) }\end{array}$ & $\begin{array}{c}\text { Crotalária juncea } \\
\text { (plantas/m²) }\end{array}$ & $\begin{array}{c}\text { Vegetação espontânea } \\
\left(\text { plantas } / \mathbf{m}^{2}\right)\end{array}$ \\
\hline Alface-americana & 25,66 a B & 34,66 a $\mathrm{AB}$ & 19,00 a B & 63,67 a A \\
\hline Repolho & 3,66 b B & 31,00 a A & 29,00 a $\mathrm{A}$ & $28,33 \mathrm{~b} \mathrm{~A}$ \\
\hline
\end{tabular}

${ }^{1}$ Médias seguidas das mesmas letras na coluna não diferem entre si pelo teste de Tuckey a $5 \%$ probabilidade.

Em relação à produção comercial das hortaliças, para a alface-americana não se observou diferença significativa entre os tratamentos, ao passo que para repolho, a maior massa fresca (MF) comercial ocorreu nas parcelas nas quais se aplicaram os tratamentos com vegetação espontânea mais adubação mineral (testemunha) e crotalária juncea (Tabela 7).

TABELA 7 - Massa fresca comercial (MF) do repolho e da alface-americana em função das plantas de cobertura ${ }^{1}$. UFLA, Lavras, MG, 2002.

\begin{tabular}{llll}
\hline \multirow{2}{*}{ Plantas cobertura } & \multicolumn{1}{c}{ Repolho } & \multicolumn{1}{c}{$\begin{array}{c}\text { Alface- } \\
\text { americana }\end{array}$} \\
\cline { 2 - 4 } & \multicolumn{3}{c}{ MF comercial(g) } \\
\hline Crotalária juncea & $1378,00 \mathrm{a}$ & $\mathrm{b}$ & $332,00 \mathrm{a}$ \\
Mucuna-preta & 1215,33 & $\mathrm{~b}$ & $409,00 \mathrm{a}$ \\
Feijão-de-porco & 1238,33 & $\mathrm{~b}$ & $294,00 \mathrm{a}$ \\
Testemunha & $1960,00 \mathrm{a}$ & & $487,00 \mathrm{a}$ \\
\hline
\end{tabular}

${ }^{1}$ Médias seguidas das mesmas letras não diferem entre si pelo teste de Tukey a $5 \%$ de probabilidade.

\section{CONCLUSÕES}

As espécies utilizadas como adubação verde mostraram-se eficientes no controle de tiririca, especialmente mucuna-preta e feijão-de-porco, possivelmente pelo efeito alelopático.

Entre as hortaliças, o cultivo de repolho foi mais eficiente do que o de alface-americana na redução da infestação de tiririca.

\section{REFERÊNCIAS BIBLIOGRÁFICAS}

AGRIANUAL. Alimentos orgânicos: selo para garantir origem e qualidade. São Paulo: FNP Consultoria \& Comércio, 2000. 66 p.
ALCÂNTARA, F. A. de; FERREIRA NETO, A. E.; PAULA, M. B. de; MESQUITA, H. A. de; MUNIZ, J. A. Adubação verde na recuperação da fertilidade de um latossolo vermelho-escuro degradado. Pesquisa Agropecuária Brasileira, Brasília, v. 35 , n. 2, p. 277-288, fev. 2000 .

ALMEIDA, F. S. de. Efeitos alelopáticos de resíduos vegetais. Pesquisa Agropecuária Brasileira, Brasília, v. 26, n. 2, p. 221-236, fev. 1991.

ALVARENGA, R. C.; COSTA, L. M. da; MOURA FILHO, W.; REGAZZI, A. J. Características de alguns adubos verdes de interesse para a conservação e recuperação de solos. Pesquisa Agropecuária Brasileira, Brasília, v. 30, n. 2, p. 175-185, fev. 1995.

CALEGARI, A. Leguminosas para adubação verde de verão no Paraná. Londrina: IAPAR, 1995. 118 p. (Circular, 80).

CARVALHO, G. J. de; FONTANÉTTI, A.; CANÇADO, C. T. Potencialidades alelopáticas da mucuna preta (Stilozobium aterrimum) e do feijão porco (Canavalia ensiformes), no controle da tiririca (Cyperus rotundus). Ciência e Agrotecnologia, Lavras, v. 26, n. 3. p. 647651, maio/jun. 2002.

COMISSÃO DE FERTILIDADE DO SOLO DO ESTADO DE MINAS GERAIS. Recomendações para o uso de corretivos e fertilizantes em Minas Gerais: 5a aproximação. Viçosa, 1999. 359 p.

EINHELLIG, F. A. Mechanisms and modes of actions of allelochemicals. In: PUTNAM, A. R.; TANG, C. S. (Eds.). The Science of allelopathy. New York: John Willey \& Sons, 1986. p. 171188 . 
FAVERO, C.; JUCKSCH, I.; ALVARENGA, R. C.; COSTA, L. M. da. Modificações na população de plantas invasoras na presença de adubos verdes. Pesquisa Agropecuária Brasileira, Brasília, v. 36, n. 11, p. 1355-1362, nov. 2001.

GLIESSMAN, R. S. Agroecologia: processos ecológicos em agricultura sustentável. Porto Alegre: UFRGS, 2000. 637 p.

GRIME, J. P. Plant strategies and vegetation process. New York: John Wiley \& Sons, 1979. 209 p.

LORENZI, H. Considerações sobre plantas daninhas no plantio direto. In: TORRADO, V. P.; RAPHAEL, A. R. Plantio direto no Brasil. Campinas: Fundação Cargill, 1984. cap. 2, p. 13-46.

MAGAlHÃES, A. C.; FRANCO, C. M. Toxidade de feijão de porco sobre a "tiririca". Bragantia, Campinas, v. 21, n. 35 , p. 53-58, jun. 1962.

OLIVEIRA, T. K. de; CARVALHO, G. J. de; MORAES, R. N. S. Plantas de cobertura e seus efeitos sobre o feijoeiro em plantio direto. Pesquisa Agropecuária Brasileira, Brasília, v. 37, n. 8, p. 1079-1087, ago. 2002.

PITELLI, R. A.; DURIGAN, J. C. Plantas daninhas no sistema de plantio direto de culturas anuais. In: ENCONTRO SUL MINEIRO SOBRE SISTEMAS DE PLANTIO DIRETO, 1., 2003, Lavras. Anais... Lavras: UFLA, 2003. CD-ROM.

SCHIMIDT, P. A.; MALUF, J. E. L.; FONTANETTI, A.; CARVALHO, G. J. de; MADEIRA, N. Influência das palhadas de mucuna preta, feijão de porco, Crotalaria juncea e vegetação espontânea na temperatura superficial do solo. In: CONGRESSO DE INICIAÇÃO CIENTÍFICA DA UFLA-CICESAL, 15.; SEMINÁRIO DE AVALAÇÃO DO PIBIC/CNPq, 9.; SEMINÁRIO DE AVALIAÇÃO DO PIBIICT/FAPEMIG, 5., 2002, Lavras. Anais... Lavras: UFLA, 2002. p. 40.

SILVEIRA NETO, F. S. Controle de plantas invasoras através de coberturas verdes consorciadas com milho. Pesquisa Agropecuária Brasileira, Brasília, v. 28, n. 10, p. 1165-1171, out. 1993. 